\title{
Effect of system tilt and seat-to-backrest angles on load sustained by shoulder during wheelchair propulsion
}

\author{
Guillaume Desroches, BSc; ${ }^{1-3 *}$ Rachid Aissaoui, PhD; ${ }^{1-3}$ Daniel Bourbonnais, $\mathbf{P h D}^{\mathbf{3}}$ \\ ${ }^{1}$ Laboratoire de Recherche en Imagerie et Orthopédie, Centre de Recherche du Centre Hospitalier de l'Université de \\ Montréal, Hôpital Notre-Dame, Montréal, Québec, Canada; ${ }^{2}$ Département de Génie de la Production Automatisée, \\ École de Technologie Supérieure, Montréal, Québec, Canada; ${ }^{3}$ Centre de Recherche Interdisciplinaire en Réadapta- \\ tion de Montréal, Site Institut de Réadaptation de Montréal, Montréal, Québec, Canada
}

\begin{abstract}
This study determined the effect of system tilt angle (STA) and seat-to-backrest angle (SBA) changes on the load sustained by the shoulder during manual wheelchair propulsion. Fourteen elderly participants (mean $+/-$ standard deviation age $68.2+/-5.2$ years) were recruited. Combinations of three STAs $\left(0^{\circ}, 5^{\circ}\right.$, and $\left.10^{\circ}\right)$ and three SBAs $\left(95^{\circ}, 100^{\circ}\right.$, and $105^{\circ}$ ) were randomly tested. The initial position of the wheel axle was held constant with respect to the participant's shoulder position in each condition (horizontal: $4 \mathrm{~cm}$ forward of shoulder, vertical: $110^{\circ}$ to $120^{\circ}$ elbow extension). The shoulder load was estimated by the joint moments. The analysis did not reveal any significant differences between shoulder joint moments (average and peak) for the various STA and SBA combinations. Changing the seat angle while keeping the wheel-axle position constant maintained the shoulder load at the same level. Thus, seat angle can be determined with the goals of user comfort and pressure modulation at the seat interface for alleviating pressure ulcers without increasing risk of overuse shoulder injuries.
\end{abstract}

Key words: injuries, load, manual wheelchair, moments, positioning, propulsion, seat, seat-to-backrest angle, shoulder, system tilt angle.

\section{INTRODUCTION}

With the constant progress of technology, wheelchair configuration and design have evolved over the years. From nonadjustable wheelchairs came customizable wheelchairs that enable clinicians, designers, and users to modify the physical aspect of the wheelchair. Modifying seat position with respect to the wheel axle, cambering the wheels, varying backrest height, and increasing handrim diameter are some examples of possible wheelchair modifications.

Van der Woude et al. stated that optimum physical performance at low energy cost can only be achieved by optimal wheelchair-user configuration (seat position, wheel camber, hand-rim diameter, etc.) [1]. This implies that the configuration of the wheelchair must be unique to each individual so that he or she can obtain a maximum performance-cost ratio. One primary determinant of propulsion performance, which influences wheelchair stability, rolling resistance, and maneuverability, is the distribution of mass with respect to the wheel axle [2]. A more rearward center of mass with respect to the wheel axle is thought to increase the user's performance and

Abbreviations: $\mathrm{MWC}=$ manual wheelchair, $\mathrm{SBA}=$ seat-tobackrest angle, SD = standard deviation, STA = system tilt angle.

*Address all correspondence to Guillaume Desroches, Laboratoire de Recherche en Imagerie et Orthopédie (LIO), Département de Génie de la Production Automatisée, École de Technologie Supérieure, A-3511, 1100, rue Notre-Dame Ouest, Montréal, Québec, Canada H3C 1K3; 514-396-8800, ext 7528; fax: 514-396-8595.

Email: guillaume.desroches.1@ens.etsmtl.ca

DOI: 10.1682/JRRD.2005.12.0178 
postural control [2] and can be achieved by changing the seat position with respect to the wheel axle.

The horizontal and vertical positions of the seat with respect to the wheel axle (and therefore the position of the center of mass) are well documented to significantly affect the biomechanics of propulsion. Lower $\left(100^{\circ}\right.$ to $120^{\circ}$ elbow extension) and more backward seat positions with respect to the wheel axle have been associated with lower electromyograph activity [3], lower push frequency [4], higher push angle [4], lower rate of rise of push force [4], smaller elbow and shoulder motions [5], lower oxygen cost, and higher mechanical efficiency [1]. Most studies based on these results agree that lower and more backward seat positions are more advantageous for the user and that an optimal wheelchair configuration could help reduce the risk of upper-limb injuries [1,3-6]. In a recent study, Mulroy et al. showed that a wheel axle placed $8 \mathrm{~cm}$ forward of the shoulder yielded a significant decrease in upward force around the shoulder [7]. The authors stated that reducing upward force could possibly diminish impingement on subacromial structures; thus, a nonoptimal wheelchair configuration could increase the risk of shoulder injuries [7]. Given the high prevalence of upper-limb pain and repetitive strain injury in manual wheelchair (MWC) users (31\%-73\%), especially around the shoulder [8-10], knowledge of the best configuration for the user is important so that risks can be reduced.

Different seating positions alter the user's propulsion technique and thus the biomechanics of propulsion [3]. Aissaoui et al. showed that tilting the seat $10^{\circ}$ signifi- cantly increased the effectiveness (tangential component) of the propulsive force in a group of elderly wheelchair users [11]. According to these results, users were more efficient during the push phase, but the authors did not estimate the load sustained by the shoulder (i.e., prime mover) [11]. Therefore, we were interested in examining whether different seat angles would prove to be more or less demanding for users, especially around the shoulder, and would help optimize wheelchair configuration. The objective of this study was to determine the effect of varying the seat-to-backrest angle (SBA) and system tilt angle (STA) on the load sustained by the shoulder during MWC propulsion.

\section{METHODS}

The data in the current study are from the same participants and protocol of an earlier study [11]. A summary of the experimental design and protocol is presented here.

\section{Participants}

We recruited 14 elderly MWC users (7 women and 7 men) for this experiment. The group's mean \pm standard deviation (SD) age was $68.2 \pm 5.2$ years. A summary of the participants' characteristics is given in Table 1. The participants' diagnoses were paraplegia $(n=3)$, tibial and/ or femoral amputation ( $n=6)$, acute anterior poliomyelitis $(n=4)$, and multiple sclerosis $(n=1)$. To participate,

Table 1.

Participant characteristics $(n=14)$.

\begin{tabular}{|c|c|c|c|c|c|}
\hline Participant & Age (yr) & Height (cm) & Weight (kg) & Sex & Diagnosis \\
\hline 1 & 68 & 142 & 54.55 & Female & Poliomyelitis \\
\hline 2 & 66 & 180 & 85.91 & Male & Paraplegia 12th thoracic \\
\hline 3 & 66 & 163 & 57.73 & Male & Bilateral tibial amputation \\
\hline 5 & 60 & 173 & 75.00 & Male & Paraplegia 3rd thoracic \\
\hline 6 & 76 & 158 & 83.18 & Female & Paraparesis \\
\hline 9 & 69 & 168 & 70.45 & Male & Poliomyelitis \\
\hline 10 & 63 & 168 & 50.00 & Female & Multiple sclerosis \\
\hline 11 & 77 & 168 & 47.73 & Male & Right femoral amputation \\
\hline 12 & 77 & 155 & 52.27 & Female & Right femoral amputation \\
\hline 13 & 69 & 158 & 79.09 & Female & Poliomyelitis \\
\hline
\end{tabular}


participants had to (1) have been propelling their MWCs on a daily basis with both hands, (2) have no history of pressure ulcer for more than 1 year, (3) be able to propel their MWCs a distance of $6 \mathrm{~m}$ in less than 30 seconds, and (4) give informed consent. All participants had a 1-year minimum duration of wheelchair use. The experiment was approved by the Lucie-Bruneau, Institut Universitaire de Gériatrie de Montréal, and École de Technologie Supérieure ethics committees.

\section{Experimental Design and Protocol}

The experimental design used a friction roller cylinder (Figure 1). The mean \pm SD resistance force applied to the roller was about $14 \pm 4 \mathrm{~N}$ (Figure 1, Fr) and maximum power output was $22.4 \pm 1.1 \mathrm{~W}$. The front wheels were locked onto the platform to prevent displacement. All participants were tested in the same custom-built wheelchair. The seat width was constant for all participants but the seat depth was adjustable to allow a $2 \mathrm{~cm}$ space between the back of the knee and the seat. The wheelchair seat and backrest could move independently of each other, allowing different angle combinations. For the experiment, we combined three different STAs $\left(0^{\circ}\right.$, $5^{\circ}$, and $\left.10^{\circ}\right)$ with three different SBAs $\left(95^{\circ}, 100^{\circ}\right.$, and $105^{\circ}$ ). Since our objective was to determine whether seating angle affects the biomechanics of propulsion, we held constant the horizontal and vertical positions of the wheel axle with respect to the participant. After the desired STA and SBA configuration was set, the height of the seat was determined when the participant's elbow angle $(\theta)$ was between $110^{\circ}$ and $120^{\circ}$ while his or her hand was positioned at the top center of the wheel (Figure 1) [1]. The horizontal position of the seat (Figure 1, H) was set in the same position with the wheel axle placed $4 \mathrm{~cm}$ forward of the shoulder marker (Figure 1). Nine configurations (3 STAs $\times 3$ SBAs) were randomly tested twice. The participant had to reach a linear speed between 0.96 and $1.01 \mathrm{~m} / \mathrm{s}$ for a trial to be valid. An occupational therapist ensured that velocity was maintained by giving verbal feedback to the participant. Linear velocity was monitored by a digital cycling computer (Bell-8, Cyclometer, Bell Sports, Canada). Each trial was followed by a 4-minute rest period.

\section{Kinematic and Kinetic Measurements}

To measure movements of the upper limbs, we placed 15 reflective markers, mounted on the right side, on the following anatomical landmarks (Figure 1): one

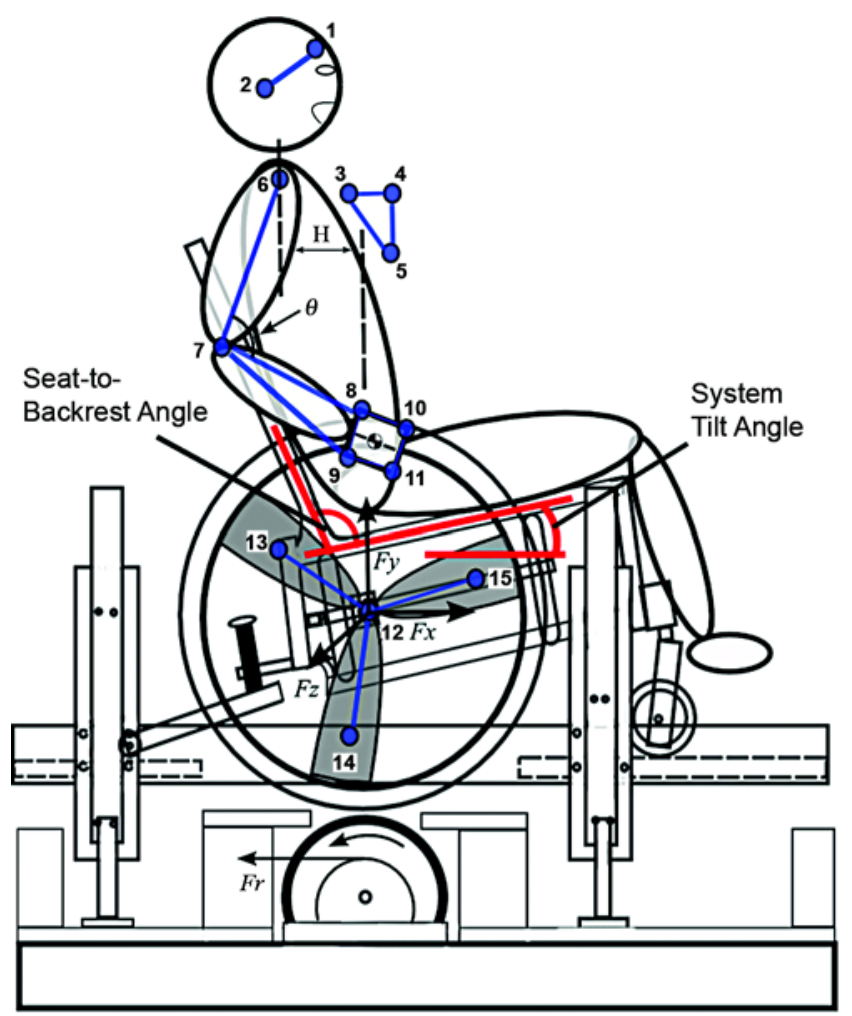

Figure 1.

Experimental ergometer used in study to obtain various seat-tobackrest and system tilt angles. Vertical (elbow angle $[\theta]$ ) and horizontal $(\mathrm{H})$ positions of wheel axle were adjustable and set at $110^{\circ}-120^{\circ}$ of elbow extension and $4 \mathrm{~cm}$ forward of shoulder, respectively. Positions of reflective markers are numbered 1-15. Origin of global coordinate system was placed at center of wheel axle. Resistance force $(F r)$ was applied to roller to create friction between cylinder and wheels. $F x=$ force at $x$-axis, $F y=$ force at $y$-axis, $F z=$ force at $z$-axis.

on the forehead (1), one on the right ear (2), three on the sternum (3-5), one on the right acromion (6), one on the lateral epicondyle of the right elbow (7), one on each of the styloid processes of the ulna and the radius (8-9), one on each of the second and fifth metacarpophalangeal joints (10-11), one on the center of the wheel to represent the origin of the global coordinate system (12), and one on each of the three beams of the wheel (13-15). The three markers on the sternum (3-5) were attached to a rigid body and helped us define a coordinate system that accounted for the movements of the trunk. Kinematic data were collected with a three-dimensional motion analysis system (Motion Analysis System, Santa Rosa, California) at a sampling frequency of $60 \mathrm{~Hz}$. The absolute error of the three-dimensional reconstruction of our system was $2.5 \mathrm{~mm}$ [12]. 
The forces and moments acting at the hand-rim level were collected at a rate of $240 \mathrm{~Hz}$ with an instrumented wheel (SMART ${ }^{\text {Wheel) }}$ [13]. The SMART ${ }^{\text {Wheel }}$ was mounted on the right side of the wheelchair. A regular wheelchair wheel was placed on the left side and weights were added so that both wheels had the same inertial characteristics. Kinetic and kinematic data were synchronized. When the participant reached a steady state of manual propulsion $(0.96-1.01 \mathrm{~m} / \mathrm{s})$ for at least 1 minute, we collected data for 10 seconds.

The origin of the global reference system was at the center of the SMART ${ }^{\text {Wheel }}$ (Figure 1). The $x$-axis was oriented in the forward direction horizontally. The $y$-axis contained the gravitational axis and was oriented in an upward direction, and the $z$-axis was obtained by the right-hand cross product.

\section{Data Processing}

The kinematic and kinetic data were filtered with a low-pass second-order Butterworth filter. The cut-off frequency of each kinematic marker and kinetic data were determined by an optimization procedure that minimized an objective function based on the autocorrelation between noise and information signal [14].

The load on the shoulder was estimated by the joint moments. We used Dumas et al.'s inverse dynamic model that applies wrench formulation and quaternion algebra [15]. The inverse dynamic described by Dumas et al. has the advantage of avoiding calculation of joint-angle sequences to determine joint forces and moments [15]. The joint moments were referenced to the trunk and expressed using Cooper et al.’s reference system (Figure 2) [16]. The joint moments corresponded to adduction/abduction, internal/external rotation, and flexion/extension in the sagittal and horizontal planes (Figure 2). All joint moments were normalized across the push phase for comparison. The push phase or push cycle started when the moment around the $z$-axis (Mz) deviated by more than 5 percent from baseline and ended when $\mathrm{Mz}$ returned and remained less than 5 percent from baseline (Figure 3) [16]. We analyzed push cycles from five consecutive cycles during the 10-second recording that met the criteria described previously. The mean and peak of each shoulder joint moment for the five cycles were computed and then averaged together to yield the mean and mean peak for the trial. The same process was repeated for the second trial. The mean and peak of both trials were averaged together.

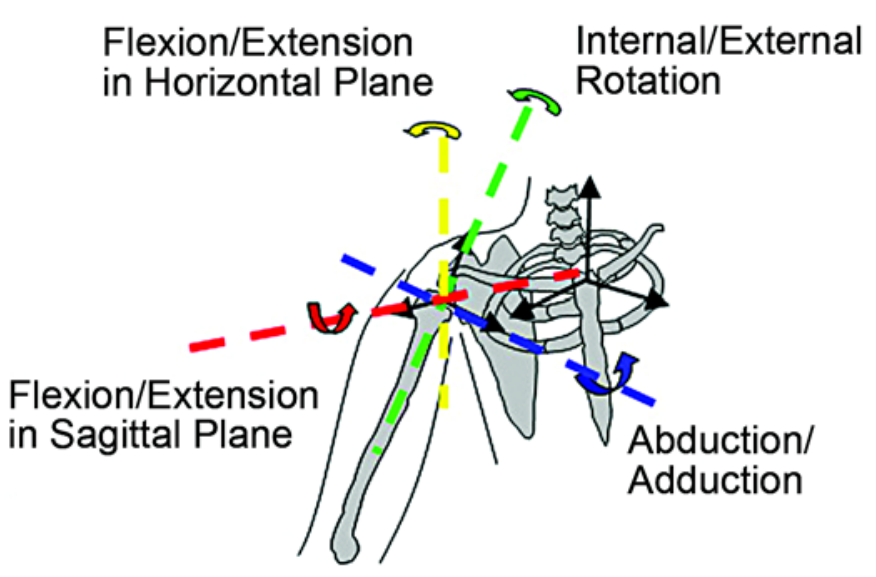

Figure 2.

Shoulder joint moments based on Cooper et al.'s reference system. Source: Cooper RA, Boninger ML, Shimada SD, Lawrence BM. Glenohumeral joint kinematics and kinetics for three coordinate system representations during wheelchair propulsion. Am J Phys Med Rehabil. 1999;78(5):435-46. [PMID: 10493454].

\section{Temporal Characteristics}

The push angle was computed with the use of kinematics. The start angle was defined as the angle between the center of mass of the hand at the beginning of the push phase and the vertical (Figure 3). We computed the hand center of mass using the positions of the four markers of the hand and the Dempster coefficient [17]. The midpoint of the distance between the ulnar and radial styloid processes and also between the fifth and second metacarpal joints were computed. Next, the center of mass was located at 0.506 percent of the distance of the line joining the two midpoints, starting from the proximal part (i.e., midpoint between the styloid and ulnar processes).

The end angle was obtained based on the position of the center of mass of the hand and the vertical at the end of the push phase. The push angle was computed by adding the start angle and the end angle. The push angle was calculated for each of the five cycles of the trial and averaged together, yielding an average push angle for the trial. The same process was repeated for the second trial. Both trials were then averaged together.

The push frequency was computed for each trial and was defined as the number of push cycles over the 10-second trial. The push frequency of the first and second trials were averaged together, yielding a mean push frequency for each condition. 
(a)

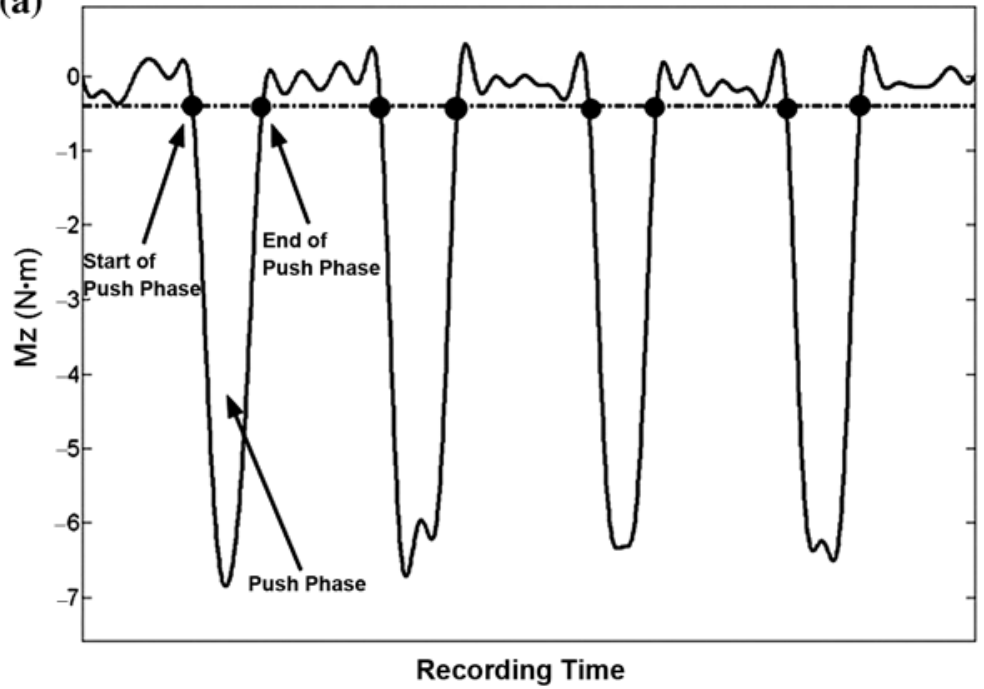

(b)

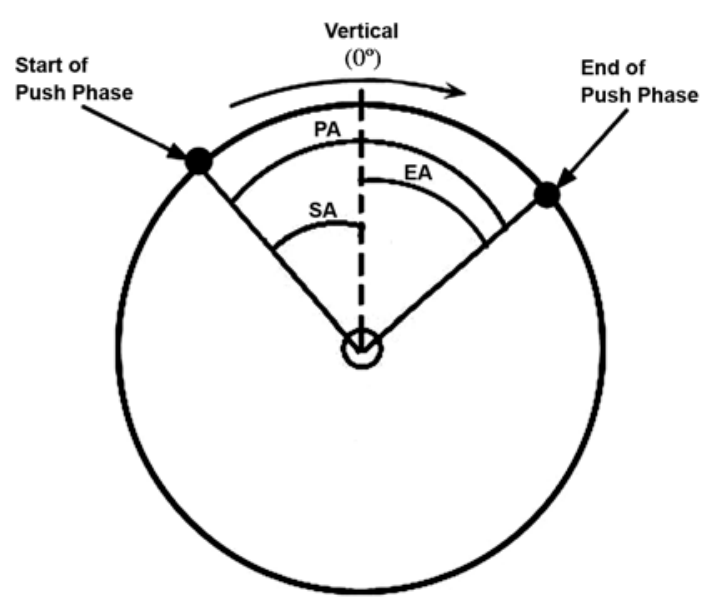

Figure 3.

(a) Determination of push phase based on moment (Mz) about hub or z-axis. Dotted line represents trigger ( $5 \%$ of baseline) that determined start and end of push phase. (b) Determination of start angle (SA), end angle (EA), and push angle (PA) for one push phase.

\section{Statistical Analysis}

We performed a two-way analysis of variance with repeated measures using Statistica software (Stat Soft Inc, Tulsa, Oklahoma). The significance level was set at $p<$ 0.05 . The two trials were averaged together. The two factors used for analysis were STA and SBA. The dependent variables were the mean and peak moments for adduction/abduction, internal/external rotation, flexion/ extension in the sagittal and horizontal plane, the average push angle, and the average push frequency of each condition. We analyzed whether the STA and/or SBA adjustments significantly affected the dependent variables. Contrast analyses were performed when significant main factors were found.

\section{RESULTS}

\section{Shoulder Joint Moments}

Figure 4 depicts a timed series of shoulder joint moments for one participant. Each curve represents a push phase computed over one trial. The shoulder joint moments are expressed in the reference system described by Cooper et al [16].

\section{Mean Moments}

The mean and standard deviation of each shoulder joint moment with respect to the seat position are given in Table 2. The highest average moments were for flexion in the sagittal plane $\left(9.88 \mathrm{~N} \cdot \mathrm{m}\right.$ [ $\left.\left.5^{\circ} \mathrm{STA}, 95^{\circ} \mathrm{SBA}\right]\right)$, internal rotation $\left(4.75 \mathrm{~N} \bullet \mathrm{m}\left[0^{\circ} \mathrm{STA}, 100^{\circ} \mathrm{SBA}\right]\right)$, flexion in the horizontal plane $\left(2.91 \mathrm{~N} \cdot \mathrm{m}\left[10^{\circ} \mathrm{STA}, 100^{\circ} \mathrm{SBA}\right]\right)$, and adduction (2.44 N•m [5 $\left.\left.5^{\circ} \mathrm{STA}, 105^{\circ} \mathrm{SBA}\right]\right)$. The statistical analysis did not reveal any significant main effects or interactions between factors on any of the average shoulder joint moments.

\section{Peak Moments}

The mean and SD of all peak shoulder joint moments with respect to STA and SBA are displayed in Table 3. The highest peak moments were for flexion in the sagittal plane $\left(15.85 \mathrm{~N} \cdot \mathrm{m}\left[0^{\circ} \mathrm{STA}, 100^{\circ} \mathrm{SBA}\right]\right)$, internal rotation $\left(7.47 \mathrm{~N} \bullet \mathrm{m}\left[0^{\circ} \mathrm{STA}, 100^{\circ} \mathrm{SBA}\right]\right)$, flexion in the horizontal plane $\left(4.90 \mathrm{~N} \cdot \mathrm{m}\left[10^{\circ} \mathrm{STA}, 100^{\circ} \mathrm{SBA}\right]\right)$, and adduction (4.63 $\left.\mathrm{N} \bullet \mathrm{m}\left[5^{\circ} \mathrm{STA}, 105^{\circ} \mathrm{SBA}\right]\right)$. Modifications to the seat angle did not yield any significant main effects or interactions between factors on any peak shoulder joint moments.

\section{Temporal Characteristics}

The mean push angle was between $38.28^{\circ}\left(10^{\circ}\right.$ STA, $\left.105^{\circ} \mathrm{SBA}\right)$ and $43.22^{\circ}\left(0^{\circ} \mathrm{STA}, 100^{\circ} \mathrm{SBA}\right)$. A significant main effect was found in the push angle for STA $\left(F_{2,26}=\right.$ $4.91, p<0.02)$ and SBA $\left(F_{2,26}=4.42, p<0.03\right)$. No interaction was found between the two factors (Table 4). Contrast analysis revealed that when compared with $10^{\circ}$ 
(a)

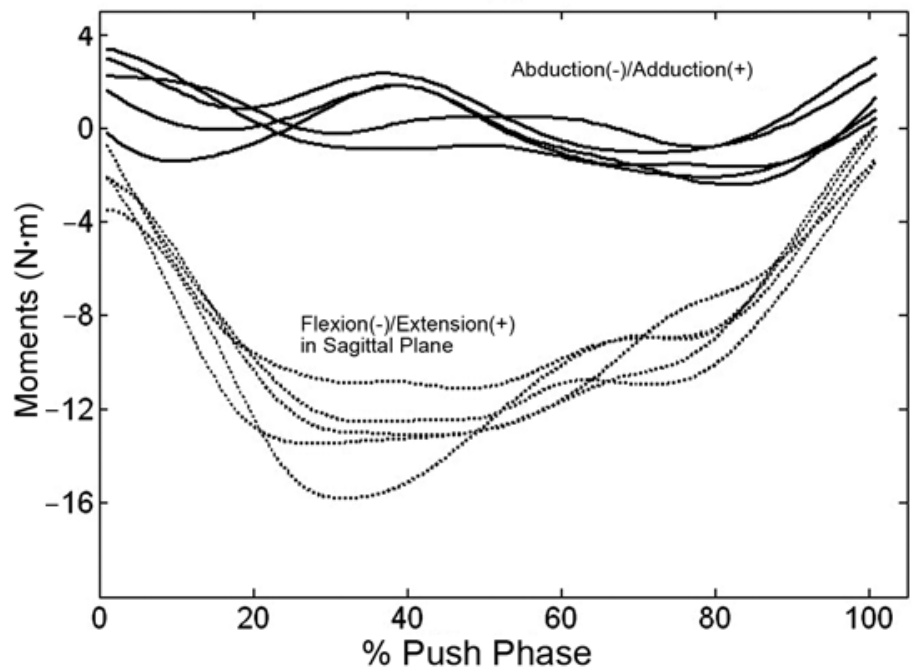

(b)

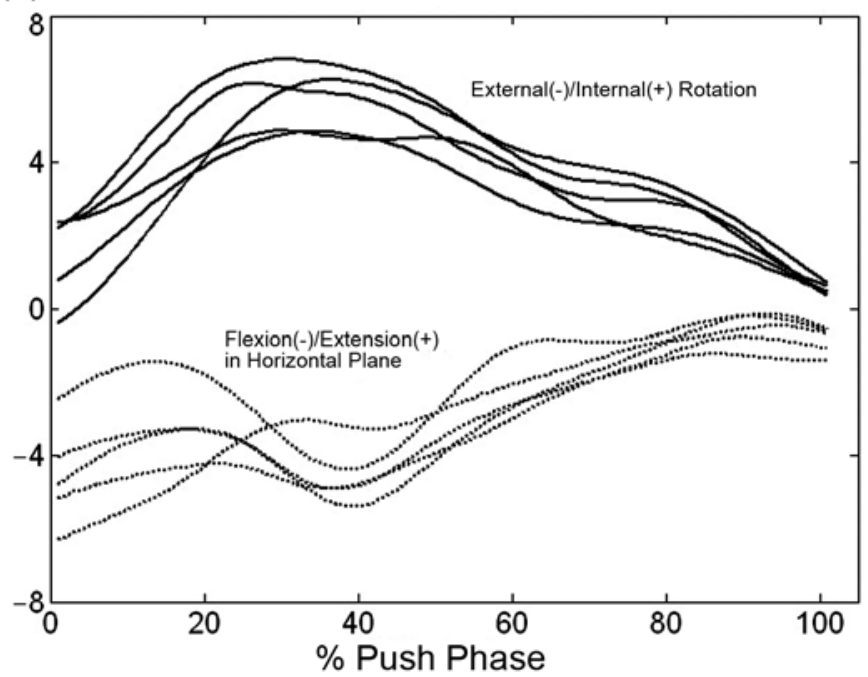

Figure 4.

Timed series of shoulder joint moments over push phase for one participant during one trial in which seat-to-backrest angle was $95^{\circ}$ and seat tilt angle was $0^{\circ}$. (a) Solid line represents shoulder joint moment for abduction/adduction and dotted line represents joint moment for flexion/ extension in sagittal plane. (b) Solid line represents shoulder joint moment for external/internal rotation and dotted line represents joint moment for flexion/extension in horizontal plane.

Table 2.

Mean \pm standard deviation $(\mathrm{N} \bullet \mathrm{m})$ shoulder joint moments for adduction, abduction, internal and external rotation, and flexion and extension in sagittal and horizontal planes for different system tilt angle (STA) and seat-to-backrest angle (SBA) configurations.

\begin{tabular}{|c|c|c|c|c|c|c|c|c|c|}
\hline STA $\left(^{\circ}\right)$ & $\operatorname{SBA}\left({ }^{\circ}\right)$ & Adduction & Abduction & $\begin{array}{l}\text { Internal } \\
\text { Rotation }\end{array}$ & $\begin{array}{l}\text { External } \\
\text { Rotation }\end{array}$ & $\begin{array}{l}\text { Flexion } \\
\text { Sagittal }\end{array}$ & $\begin{array}{c}\text { Extension } \\
\text { Sagittal }\end{array}$ & $\begin{array}{c}\text { Flexion } \\
\text { Horizontal }\end{array}$ & $\begin{array}{c}\text { Extension } \\
\text { Horizontal }\end{array}$ \\
\hline \multirow[t]{3}{*}{0} & 95 & $2.07 \pm 0.69$ & $1.99 \pm 1.55$ & $4.43 \pm 1.84$ & $0.74 \pm 0.77$ & $9.86 \pm 3.27$ & $1.57 \pm 1.14$ & $2.68 \pm 1.41$ & $0.65 \pm 0.28$ \\
\hline & 100 & $2.08 \pm 0.65$ & $1.97 \pm 1.18$ & $4.75 \pm 2.03$ & $0.74 \pm 0.72$ & $9.85 \pm 3.47$ & $1.64 \pm 1.07$ & $2.88 \pm 1.16$ & $0.39 \pm 0.22$ \\
\hline & 105 & $2.24 \pm 0.67$ & $2.35 \pm 1.60$ & $3.98 \pm 1.75$ & $0.82 \pm 0.62$ & $9.08 \pm 3.57$ & $1.50 \pm 1.12$ & $2.55 \pm 1.19$ & $0.77 \pm 0.52$ \\
\hline \multirow[t]{3}{*}{5} & 95 & $1.95 \pm 0.40$ & $1.94 \pm 1.43$ & $4.30 \pm 1.76$ & $0.69 \pm 0.42$ & $9.88 \pm 3.48$ & $1.83 \pm 0.73$ & $2.82 \pm 1.36$ & $0.54 \pm 0.40$ \\
\hline & 100 & $2.13 \pm 0.66$ & $2.20 \pm 1.61$ & $3.96 \pm 1.69$ & $1.19 \pm 0.84$ & $8.98 \pm 3.46$ & $1.57 \pm 0.99$ & $2.43 \pm 0.91$ & $0.93 \pm 0.83$ \\
\hline & 105 & $2.44 \pm 0.87$ & $1.79 \pm 1.11$ & $4.18 \pm 1.91$ & $0.75 \pm 0.46$ & $8.63 \pm 4.00$ & $1.33 \pm 0.78$ & $2.81 \pm 1.32$ & $0.55 \pm 0.35$ \\
\hline \multirow[t]{3}{*}{10} & 95 & $2.34 \pm 1.33$ & $1.93 \pm 1.01$ & $4.39 \pm 1.92$ & $0.84 \pm 0.53$ & $9.40 \pm 4.14$ & $1.59 \pm 0.85$ & $2.76 \pm 1.38$ & $0.75 \pm 0.45$ \\
\hline & 100 & $2.18 \pm 0.93$ & $1.63 \pm 1.17$ & $3.94 \pm 1.94$ & $1.17 \pm 1.03$ & $8.41 \pm 3.93$ & $1.21 \pm 0.80$ & $2.91 \pm 1.56$ & $0.85 \pm 0.61$ \\
\hline & 105 & $2.12 \pm 0.84$ & $1.95 \pm 1.05$ & $4.35 \pm 1.84$ & $1.07 \pm 0.41$ & $9.49 \pm 3.87$ & $1.60 \pm 0.65$ & $2.88 \pm 1.19$ & $0.67 \pm 0.58$ \\
\hline
\end{tabular}

Table 3.

Mean \pm standard deviation $(\mathrm{N} \bullet \mathrm{m})$ peak shoulder joint moments for adduction, abduction, internal and external rotation, and flexion and extension in sagittal and horizontal planes for different system tilt angle (STA) and seat-to-backrest angle (SBA) configurations.

\begin{tabular}{|c|c|c|c|c|c|c|c|c|c|}
\hline $\operatorname{STA}\left({ }^{\circ}\right)$ & $\operatorname{SBA}\left({ }^{\circ}\right)$ & Adduction & Abduction & $\begin{array}{l}\text { Internal } \\
\text { Rotation }\end{array}$ & $\begin{array}{l}\text { External } \\
\text { Rotation }\end{array}$ & $\begin{array}{l}\text { Flexion } \\
\text { Sagittal }\end{array}$ & $\begin{array}{c}\text { Extension } \\
\text { Sagittal }\end{array}$ & $\begin{array}{c}\text { Flexion } \\
\text { Horizontal }\end{array}$ & $\begin{array}{c}\text { Extension } \\
\text { Horizontal }\end{array}$ \\
\hline 0 & 100 & $3.99 \pm 1.22$ & $3.46 \pm 2.06$ & $7.47 \pm 3.12$ & $0.85 \pm 0.81$ & $15.85 \pm 6.15$ & $1.80 \pm 1.06$ & $4.64 \pm 1.59$ & $0.56 \pm 0.32$ \\
\hline \multirow[t]{3}{*}{5} & 95 & .67 & 2.36 & $6.77 \pm 2.73$ & $0.84 \pm 0.60$ & $15.72 \pm 6.34$ & 0.91 & $4.40 \pm 1.92$ & \pm 0.67 \\
\hline & 100 & $3.98=$ & 3.63 & $6.13 \pm 2.44$ & $1.66 \pm 1.34$ & $14.29 \pm 6.19$ & $1.88 \pm 1.18$ & $4.09 \pm 1.44$ & $1.51 \pm 1.48$ \\
\hline & 105 & $4.63 \pm 1.64$ & $3.02 \pm 1.90$ & $6.51 \pm 2.85$ & $0.93 \pm 0.66$ & $13.44 \pm 6.29$ & $1.62 \pm 1.08$ & $4.62 \pm 1.60$ & $0.83 \pm 0.64$ \\
\hline \multirow{2}{*}{10} & 100 & $4.10 \pm 1.56$ & $2.73 \pm 2.05$ & $6.21 \pm 3.12$ & $1.45 \pm 1.31$ & $13.44 \pm 7.15$ & $1.37 \pm 0.89$ & $4.90 \pm 2.61$ & $1.31 \pm 1.03$ \\
\hline & 105 & $3.82 \pm 1.31$ & $3.38 \pm 1.83$ & $6.85 \pm 2.89$ & $1.33 \pm 0.55$ & $14.70 \pm 6.22$ & $1.77 \pm 0.70$ & $4.58 \pm 1.53$ & $1.03 \pm 1.03$ \\
\hline
\end{tabular}


Table 4.

Mean \pm standard deviation push angle for each system tilt angle (STA) and seat-to-backrest angle (SBA) configuration for 14 participants.

\begin{tabular}{ccc}
\hline STA $\left(^{\circ}\right)$ & SBA $\left.^{\circ}\right)$ & Push Angle $\left(^{\circ}\right)$ \\
\hline 0 & 95 & $41.74 \pm 11.01$ \\
& 100 & $43.22 \pm 11.61$ \\
& $105^{*}$ & $40.54 \pm 8.19$ \\
\hline 5 & 95 & $43.21 \pm 10.35$ \\
& 100 & $42.01 \pm 9.26$ \\
& $105^{*}$ & $39.91 \pm 9.49$ \\
\hline $10 \dagger$ & 95 & $41.12 \pm 9.42$ \\
& 100 & $40.07 \pm 8.38$ \\
& $105^{*}$ & $38.28 \pm 10.66$
\end{tabular}

*Significant difference between $105^{\circ} \mathrm{SBA}$ and $100^{\circ} \mathrm{SBA}, p<0.05$

${ }^{\dagger}$ Significant difference between $10^{\circ}$ STA and both $0^{\circ}$ and $5^{\circ}$ STA, $p<0.05$.

STA, the $0^{\circ}$ and $5^{\circ}$ STAs significantly increased the total push angle for all SBAs combined (Table 4). According to the analysis, a $105^{\circ}$ SBA had a significantly lower push angle when compared with a $100^{\circ}$ SBA for all STAs combined.

The mean push frequency varied from $1.11 \mathrm{push} / \mathrm{s}\left(5^{\circ}\right.$ $\left.\mathrm{STA}, 95^{\circ} \mathrm{SBA}\right)$ to $1.17 \mathrm{push} / \mathrm{s}\left(10^{\circ} \mathrm{STA}, 100^{\circ}\right.$ and $105^{\circ}$ SBA). The mean push frequency for all positions was 1.16 push/s. The analysis did not reveal any significant main effect or interactions between factors in the push frequency for any STA and SBA combination (Table 5).

\section{DISCUSSION}

In this study, we determined whether modifying the wheelchair configuration affected the load sustained by the shoulder. Our analysis did not reveal any significant changes in either average or peak shoulder joint moments. This suggests that participants did not need to adjust their torque production around the shoulder to counter the changes in STA and SBA to maintain the same speed. One possible explanation why no significant differences were found in the shoulder joint moments for various seat angles is that the initial horizontal and vertical positions of the wheel axle were kept constant with respect to the shoulder position in each condition. In the current experiment, the height was set so that elbow extension was about $120^{\circ}$, which gives the highest mechanical efficiency [1] and reduces shoulder torque (in the sagittal plane) [18] when compared with a higher seat position. The horizontal position of the wheel axle was
Table 5.

Mean \pm standard deviation push frequency for each system tilt angle (STA) and seat-to-backrest angle (SBA) configuration for 14 participants.

\begin{tabular}{ccc}
\hline STA $\left(^{\circ}\right)$ & SBA $^{\circ}$ ) & Push Frequency (push/s) \\
\hline 0 & 95 & $1.15 \pm 0.46$ \\
& 100 & $1.16 \pm 0.38$ \\
& 105 & $1.12 \pm 0.41$ \\
\hline 5 & 95 & $1.11 \pm 0.46$ \\
& 100 & $1.16 \pm 0.44$ \\
& 105 & $1.14 \pm 0.42$ \\
\hline 10 & 95 & $1.16 \pm 0.38$ \\
& 100 & $1.17 \pm 0.40$ \\
& 105 & $1.17 \pm 0.49$ \\
\hline \hline
\end{tabular}

located about $4 \mathrm{~cm}$ forward of the shoulder. We chose this distance based on reports in the literature that a forward axle position with respect to the shoulder has biomechanical advantages [2,4]. In addition, Gutierrez et al. recently showed that a horizontal wheel axle position of $8 \mathrm{~cm}$ forward of the shoulder yielded significantly lower peak activity of the propulsive muscles (i.e., pectorialis major, anterior deltoid) and could reduce the risk of shoulder muscle fatigue and injury [19].

The results of the aforementioned studies suggest that the most important parameter in wheelchair positioning is the location of the wheel axle with respect to the user's morphology [1-2,4,18-19]. Our results concur with these findings, since the shoulder joint moments were not influenced by STA or SBA modifications. Therefore, one can modify the seat angle without compromising the musculoskeletal structures of the shoulder or increasing the load sustained by the shoulder if the initial position of the wheel axle is kept constant to the user's morphology. Moreover, we believe that as long as the horizontal position of the wheel axle is located forward of the shoulder (e.g., $4 \mathrm{~cm}, 8 \mathrm{~cm}$ ) and the height is between $110^{\circ}$ to $120^{\circ}$ elbow extension, shoulder load will be minimized. Future studies on different axle positions are needed to test this hypothesis.

Changing the STA and/or SBA can be done with the aim of increasing the user's comfort. Hirota et al. showed that an elderly population was significantly more comfortable when the SBA was between $95^{\circ}$ and $111^{\circ}$ than when it was less than $94^{\circ}$ [20]. Similar findings were also reported by Lacoste et al. [21], who studied the use of power tilt/recline systems among 40 wheelchair users. They found that 97 percent of the users surveyed used this system on a daily basis. The main reasons that the users 
modified their seating angles were to increase comfort and to modulate the pressure at the seat interface. By tilting the seat backward, clinicians and users could modify pressure distribution at the seat interface by shifting the weight toward the back and thereby reducing pressure under the buttocks [22]. Reduction of pressure under the buttocks by modification of the seating angle could, along with other means (i.e., pressure relief cushions), help prevent pressure ulcers [23-24]. Pressure ulcers are frequent among wheelchair users, especially among the elderly population [25].

Aissaoui et al. stated that tilting the seat backward increases the fraction of effective force during propulsion [11]. They suggested that as long as the direction line of the resulting force intersects the segment defined by the shoulder and elbow, the stress at the shoulder joint should be minimized [11]. Our results support Aissaoui et al.'s idea, since the shoulder joint moments were not significantly increased when the seat was tilted backward. This result suggests that tilting the seat backward enables the user to propel with a more efficient resulting force at the hand rim without increased stress on the shoulder. Higher propulsion efficiency without significantly increased shoulder load could imply a more optimal wheelchair configuration for the participants studied here.

Our analysis revealed that tilting the system by $10^{\circ}$ significantly decreased the push angle. However, the differences found here were small $\left(\sim 2^{\circ}\right)$ and could have been caused by measurement errors. To determine the uncertainty of our angle measurements, we performed a simple sensitivity analysis. The Motion Analysis System that we used to determine the marker positions has a $2.5 \mathrm{~mm}$ reconstruction error [12]. The analysis revealed an uncertainty of $\pm 0.5^{\circ}$. Our uncertainty, computed by kinematics, was lower than that for the same angle computed by kinetic measurements, which could reach $16^{\circ}$ [26]. The significant differences that we found in the push angle $\left(\sim 2^{\circ}\right)$ are four times larger than the uncertainty of $\pm 0.5^{\circ}$. Therefore, the sensitivity analysis suggests that the significant differences found in our push angle were consistent but small. These approximately $2^{\circ}$ differences could be explained by less hand excursion near the end of the push phase caused by a more reclined position.

Our analysis did not show significant changes for the push frequency. Samuelsson et al. tested 12 subjects with paraplegia and found a significant decrease in push frequency when the system was tilted from $5^{\circ}$ to $12^{\circ}$ for a speed of $0.8 \mathrm{~m} / \mathrm{s}$ [27]. However, their seat angles were accompanied by different vertical and horizontal axle positions, which have been shown to affect push frequency [4]. Samuelsson et al.'s results combined with ours suggest that the push frequency is affected more by variations in the position of the wheel axle than by variations in STA or SBA.

The main limitation of our study is that we used an experimental ergometer and custom-built wheelchair rather than the participants' own wheelchairs. The seat width was not adjustable to the participants, which could have influenced the propulsion style. However, the seat was large enough to fit each participant and no major complaints about discomfort were reported. Therefore, we are confident that the experimental wheelchair represented as closely as possible the participants' actual wheelchairs, given the constraints of our experimental procedure (i.e., axle position). Moreover, we used the custom wheelchair to test different seating angles that would have been difficult to accomplish with the participants' own wheelchairs. Since the wheels were fixed to the ergometer, participants could not have experienced the possible instability yielded by changes in the seating angle. Even though the experimental ergometer gives rise to limitations, it is still a useful and valid tool for evaluating people with disabilities who use MWCs for locomotion [28].

Our study population was MWC users over 65 years of age. We focused on this population because they represent the majority of MWC users [29]. The sample was heterogeneous because the diagnoses among the elderly MWC population vary widely and none is predominant [29]. Thus, the nonhomogeneity of the sample, in our view, better represents the population of MWC users over 65. Moreover, studies have shown that only 45 percent of elderly MWC users in a nursing home were able to propel by themselves and the percentage of time they were observed propelling was low ( 4\%) [30]. This low propulsion rate was associated with muscle weakness and pain during propulsion [30]. Nichols et al. showed that more than 40 percent of elderly MWC users complained of pain around the shoulder [31]. Therefore, biomechanical studies of elderly MWC users are important for helping them maintain their independence level and preventing injuries.

To our knowledge, no other study has measured shoulder joint moments in elderly MWC users; however, shoulder loads have been analyzed in other populations (e.g., spinal cord injury, athletes, nondisabled). A summary of these studies is presented in Table 6. Across all studies 
Table 6.

Comparison of peak shoulder moments measured during manual wheelchair propulsion in different studies.

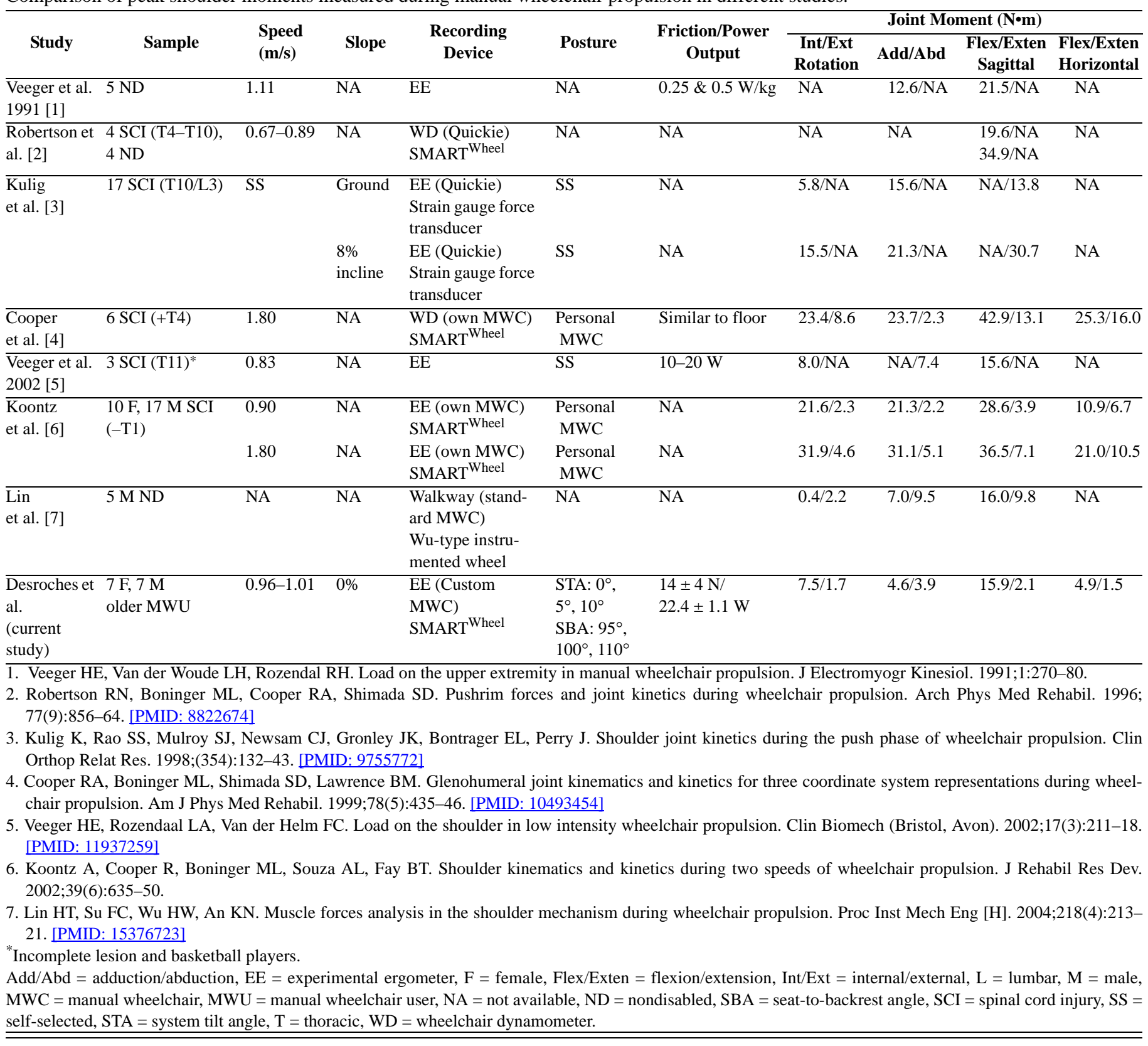

reviewed, the peak flexion and extension moments ranged from 3.9 [32] to $43 \mathrm{~N} \bullet \mathrm{m}$ [16], the peak adduction and abduction moments ranged from 2.3 [16] to $31.1 \mathrm{~N} \bullet \mathrm{m}$ [32], and the peak internal and external rotation moments ranged from 0.4 [33] to $31.9 \mathrm{~N} \cdot \mathrm{m}$ [32]. A closer look at Table 6 reveals that shoulder joint moments varied greatly among the different studies. This may be attributed to different velocities of propulsion, slopes, populations, friction, recording devices (e.g., experimental ergometer, own wheelchair, push-rim force recording), and propulsion techniques. Our results are similar to those of Veeger et al. [34], who used approximately the same speed $(0.83 \mathrm{~m} / \mathrm{s})$ and power output $(10-20 \mathrm{~W})$. This finding suggests that shoulder joint moments depend more on the experimental procedure and design, since our populations were different. Therefore, the various experimental settings, as summarized in Table 6, make comparisons difficult between studies and limit interpretation of the results to the specific 
experimental design and protocol, as Martin et al. suggested [27]. Nevertheless, shoulder joint moments give insight into the load sustained by muscles during a specific movement and have been correlated with compressive and contact forces around the shoulder joint [34-35]. Thus, shoulder joint moments can provide information on the relative demands of different situations or configurations on the shoulder. In this study, no significant changes in shoulder joint moments were noted for the different wheelchair configurations. Although not studied here, the propulsion technique could have varied for different wheelchair configurations, as suggested by Masse et al. [3], and influenced shoulder torque. In future work, we will try to establish the relationship between propulsion pattern and shoulder joint moments.

\section{CONCLUSIONS}

Results from this study show that modifying the STA and SBA while keeping the wheel axle constant with respect to the participant's shoulder did not significantly increase shoulder joint moments in a group of elderly MWC users. Therefore, wheelchair positioning can be determined according to what is most comfortable to the user and will best modulate pressure at the seat interface without increasing the risk of shoulder injuries. The clinical application of our findings are somewhat limited, since keeping the wheel axle constant with respect to the participant requires specific tools that are not always easily accessible to clinicians. However, the results provide a good basis for future work, since we showed that keeping the axle position constant to the participant's shoulder allows a certain maneuverability in modifying seating without increasing the user's shoulder load. This finding could lead to other research and help optimize wheelchair positioning.

\section{ACKNOWLEDGMENTS}

We would like to thank Patrice Huot for assistance in revising the text.

This material was based on work supported by the MENTOR program, a strategic training initiative of the Canadian Institutes of Health Research and the Natural Science and Engineering Research Council of Canada (NSERC-203490).
The authors have declared that no competing interests exist.

\section{REFERENCES}

1. Van der Woude LH, Veeger DJ, Rozendal RH, Sargeant TJ. Seat height in handrim wheelchair propulsion. J Rehabil Res Dev. 1989;26(4):31-50. [PMID: 2600867]

2. Brubaker CE. Wheelchair prescription: An analysis of factors that affect mobility and performance. J Rehabil Res Dev. 1986;23(4):19-26. [PMID: 3820118]

3. Masse LC, Lamontagne M, O'Riain MD. Biomechanical analysis of wheelchair propulsion for various seating positions. J Rehabil Res Dev. 1992;29(3):12-28. [PMID: 1640378]

4. Boninger ML, Baldwin M, Cooper RA, Koontz A, Chan L. Manual wheelchair pushrim biomechanics and axle position. Arch Phys Med Rehabil. 2000;81(5):608-13. [PMID: 10807100]

5. Hughes CJ, Weimar WH, Sheth PN, Brubaker CE. Biomechanics of wheelchair propulsion as a function of seat position and user-to-chair interface. Arch Phys Med Rehabil. 1992;73(3):263-69. [PMID: 1543431]

6. Kotajarvi BR, Sabick MB, An KN, Zhao KD, Kaufman KR, Basford JR. The effect of seat position on wheelchair propulsion biomechanics. J Rehabil Res Dev. 2004;41(3B): 403-14. [PMID: 15543458]

7. Mulroy SJ, Newsam CJ, Gutierrez DD, Requejo P, Gronley JK, Haubert LL, Perry J. Effect of fore-aft seat position on shoulder demands during wheelchair propulsion: Part 1. A kinetic analysis. J Spinal Cord Med. 2005;28(3):214-21. [PMID: 16048139]

8. Bayley JC, Cochran TP, Sledge CB. The weight-bearing shoulder. The impingement syndrome in paraplegics. J Bone Joint Surg Am. 1987;69(5):676-78. [PMID: 3597466]

9. Boninger ML, Cooper RA. Repetitive strain injuries in manual wheelchair users. In: Van der Woude LH, Hopman MT, Van Kamenade, editors. Biomedical aspect of manual wheelchair propulsion. Amsterdam (the Netherlands): IOS Press; 1999.

10. Sie IH, Waters RL, Adkins RH, Gellman H. Upper extremity pain in the postrehabilitation spinal cord injured patient. Arch Phys Med Rehabil. 1992;73(1):44-48. [PMID: 1729973]

11. Aissaoui R, Arabi H, Lacoste M, Zalzal V, Dansereau J. Biomechanics of manual wheelchair propulsion in elderly: System tilt and back recline angles. Am J Phys Med Rehabil. 2002;81(2):94-100. [PMID: 11807343]

12. Aissaoui R, Allard P, Junqua A, Frossard L, Duhaime M. Internal work estimation in three-dimensional gait analysis. Med Biol Eng Comput. 1996;34(6):467-71. [PMID: 9039750] 
13. Asato KT, Cooper RA, Robertson RN, Ster JF. SMARTWheels: Development and testing of a system for measuring manual wheelchair propulsion dynamics. IEEE Trans Biomed Eng. 1993;40(12):1320-24. [PMID: 8125507]

14. Cappello A, La Palombara PF, Leardini A. Optimization and smoothing techniques in movement analysis. Int $\mathrm{J}$ Biomed Comput. 1996;41(3):137-151. [PMID: 8872190]

15. Dumas R, Aissaoui R, De Guise JA. A 3D generic inverse dynamic method using wrench notation and quaternion algebra. Comput Methods Biomech Biomed Engin. 2004; 7(3):159-66. [PMID: 15512759]

16. Cooper RA, Boninger ML, Shimada SD, Lawrence BM. Glenohumeral joint kinematics and kinetics for three coordinate system representations during wheelchair propulsion. Am J Phys Med Rehabil. 1999;78(5):435-46. [PMID: 10493454$]$

17. Dempster WT (University of Michigan, MI). Space requirements of the seated operator: Geometrical, kinematic, and mechanical aspects of the body with special reference to the limbs. Wright-Patterson Air Force Base (OH): Wright Air Development Center, Air Research and Development Command, United States Air Force; 1955 Jul. Report No: WADC TR-55-159. Contract No.: AF 18(600-43).

18. Richter WM. The effect of seat position on manual wheelchair propulsion biomechanics: A quasi-static model-based approach. Med Eng Phys. 2001;23(10):707-12.

[PMID: 11801412]

19. Gutierrez DD, Mulroy SJ, Newsam CJ, Gronley JK, Perry J. Effect of fore-aft seat position on shoulder demands during wheelchair propulsion: Part 2. An electromyographic analysis. J Spinal Cord Med. 2005;28(3):222-29.

[PMID: 16048140$]$

20. Hirota K, Kotani T, Ishii T, Matsuoka T, Terada N, Nishimatsu T, Toba E. Influence of angle of back for sitting comfort of wheelchair. In: Proceedings of the 19th IEEE Instrumentation and Measurement Technology Conference. Vol. 2. 2002 May 21-23; Anchorage, Alaska. New York (NY): IEEE; 2002. p. 907-12.

21. Lacoste M, Weiss-Lambrou R, Allard M, Dansereau J. Powered tilt/recline systems: Why and how are they used? Assist Technol. 2003;15(1):58-68. [PMID: 14760982]

22. Aissaoui R, Lacoste M, Dansereau J. Analysis of sliding and pressure distribution during a repositioning of persons in a simulator chair. IEEE Trans Neural Syst Rehabil Eng. 2001;9(2):215-24. [PMID: 11474974]

23. Brienza DM, Karg PE, Geyer MJ, Kelsey S, Trefler E. The relationship between pressure ulcer incidence and buttockseat cushion interface pressure in at-risk elderly wheelchair users. Arch Phys Med Rehabil. 2001;82(4):529-33.

[PMID: 11295017]

24. Edlich RF, Winters KL, Woodard CR, Buschbacher RM, Long WB, Gebhart JH, Ma EK. Pressure ulcer prevention.
J Long Term Eff Med Implants. 2004;14(4):285-304. [PMID: 15447627]

25. Chen Y, Devivo MJ, Jackson AB. Pressure ulcer prevalence in people with spinal cord injury: Age-period-duration effects. Arch Phys Med Rehabil. 2005;86(6):1208-13. [PMID: 15954061]

26. Cooper RA, Boninger ML, VanSickle DP, Robertson RN, Shimada SD. Uncertainty analysis for wheelchair propulsion dynamics. IEEE Trans Rehabil Eng. 1997;5(2):130-39. [PMID: 9184899]

27. Samuelsson KA, Tropp H, Nylander E, Gerdle B. The effect of rear-wheel position on seating ergonomics and mobility efficiency in wheelchair users with spinal cord injuries: A pilot study. J Rehabil Res Dev. 2004;41(1):65-74. [PMID: 15273899]

28. Martin X, Tordi N, Bourgenot MP, Rouillon JD. Critical analysis of apparatus and evaluation methods for determination of physical capacity of spinal cord injured people using wheelchair. Sci Sports. 2002;17(5):209-19.

29. Kaye HS, Kang T, LaPlante MP. Mobility device use in the United States. Disability statistics report 14. Washington (DC): U.S. Department of Education, National Institute on Disability and Rehabilitation Research; 2000.

30. Simmons SF, Schnelle JF, MacRae PG, Ouslander JG. Wheelchairs as mobility restraints: Predictors of wheelchair activity in nonambulatory nursing home residents. J Am Geriatr Soc. 1995;43(4):384-88. [PMID: 7706628]

31. Nichols PJ, Norman PA, Ennis JR. Wheelchair user's shoulder? Shoulder pain in patients with spinal cord lesions. Scand J Rehabil Med. 1979;11(1):29-32.

[PMID: 419395]

32. Koontz AM, Cooper RA, Boninger ML, Souza AL, Fay BT. Shoulder kinematics and kinetics during two speeds of wheelchair propulsion. J Rehabil Res Dev. 2002;39(6):635-50.

33. Lin HT, Su FC, Wu HW, An KN. Muscle forces analysis in the shoulder mechanism during wheelchair propulsion. Proc Inst Mech Eng [H]. 2004;218(4):213-21. [PMID: 15376723]

34. Veeger HE, Rozendaal LA, Van der Helm FC. Load on the shoulder in low intensity wheelchair propulsion. Clin Biomech (Bristol, Avon). 2002;17(3):211-18. [PMID: 11937259]

35. Praagman M, Stokdijk M, Veeger HE, Visser B. Predicting mechanical load of the glenohumeral joint, using net joint moments. Clin Biomech (Bristol, Avon). 2000;15(5):315-21. [PMID: 10758291]

Submitted for publication December 6, 2005. Accepted in revised form June 12, 2006. 